2015-03-31

Evaluation of ecosystem-based marine management strategies based on risk assessment

\title{
Piet, GJ
}

http://hdl.handle.net/10026.1/3403

10.1016/j.biocon.2015.03.011

Biological Conservation

Elsevier BV

All content in PEARL is protected by copyright law. Author manuscripts are made available in accordance with publisher policies. Please cite only the published version using the details provided on the item record or document. In the absence of an open licence (e.g. Creative Commons), permissions for further reuse of content should be sought from the publisher or author. 
Title: Evaluation of ecosystem-based management strategies based on risk assessment

Authors: Gerjan J. Piet ${ }^{1 *}$, Ruud H. Jongbloed ${ }^{1}$, Antony M. Knights ${ }^{2,3}$, Jacqueline E. Tamis ${ }^{1}$, Anneke J. Paijmans ${ }^{1}$, Marieken T. van der Sluis ${ }^{1}$, Pepijn de Vries ${ }^{1}$, Leonie A. Robinson ${ }^{2}$

\author{
Affiliation: \\ ${ }^{1}$ Institute for Marine Resources and Ecosystem Studies (IMARES), Haringkade 1, 1976 CP, IJmuiden. The Netherlands. \\ ${ }^{2}$ School of Environmental Sciences, University of Liverpool, Nicholson Building, Liverpool. L69 3GP. UK. \\ ${ }^{3}$ Present address: Marine Biology and Ecology Research Centre, Plymouth University, Drake Circus, Plymouth. UK.
}

*Corresponding Author: Tel: +31 (0)317 487188; Email: gerjan.piet@,wur.nl. Wageningen IMARES

P.O. box 68,1970 AB IJmuiden, The Netherlands

\begin{abstract}
This study presents a comprehensive and generic framework that provides a typology for the identification and selection of consistently defined ecosystem-based management measures and allows a coherent evaluation of these measures based on their performance to achieve policy objectives. The performance is expressed in terms of their reduction of risk of an adverse impact on the marine ecosystem. This typology consists of two interlinked aspects of a measure, i.e. the "Focus" and the "Type". The "Focus" is determined by the part of the impact chain (Driver-Pressure-State) the measure is supposed to mitigate or counteract. The "Type" represents the physical measure itself in terms of how it affects the impact chain directly; we distinguish Spatio-temporal distribution controls, Input and Output controls, Remediation and Restoration measures. The performance of these measures in terms of their reduction in risk of adverse impacts was assessed based on an explicit consideration of three time horizons: past, present and future. Application of the framework in an integrated management strategy evaluation of a suite of measures, shows that depending on the time horizon, different measures perform best. "Past" points to measures targeting persistent pressures (e.g. marine litter) from past activities. "Present" favours measures targeting a driver (e.g. fisheries) that has a high likelihood of causing adverse impacts. "Future" involves impacts that both have a high likelihood of an adverse impact, as well as a long time to return to pre-impacted condition after the implementation of appropriate management, e.g. those caused by permanent infrastructure or persistent pressures such as marine litter or specific types of pollution.
\end{abstract}

\title{
Key words
}

DPSIR; Ecosystem-based management; Spatio-temporal distribution controls; Remediation; Restoration; Marine Strategy Framework Directive

\section{Introduction}

All marine ecosystems are impacted by human activities (e.g. Glover and Smith 2003; Halpern et al. 2007) and in many cases, the exploitation of resources is occurring at an unsustainable rate resulting in a deteriorated ecosystem. Impacts are caused by the multitude of sectors in operation to exploit a wide range of habitats and species (ecosystem components), thereby forming a complex network of interactions (Leslie and McLeod, 2007; Liu et al., 2007; Knights et al., 2013) that may cause harm to the environment (Levin et al., 2009; Goodsir, submitted). This has left current sectoral approaches to the management of marine and coastal resources apparently incapable of conserving the marine ecosystem and exploitation rates remaining unsustainable (Smith et al., 2007). A widely promoted solution is an ecosystem approach to management also known as ecosystem-based management (EBM) (Airoldi \& Beck, 2007; EC, 2008; Halpern et al. 2007); a concept in which the network of impacts is identified and managed. However, the number of impacts can make the identification and management of detrimental pathways difficult (Bottrill et al., 2008; but see Knights et al., 2013) and presents a major challenge to resource managers in transforming the ecosystem approach from a concept into an operational framework (Leslie and McLeod, 2007). This challenge can be addressed 
by the development of a comprehensive generic framework for integrated decision-making on the exploitation of marine resources.

The effective management of human impacts requires that the pathways through which activities cause harm are identified (Fletcher et al., 2010; Leslie and McLeod, 2007). Linkage-based frameworks (e.g. DPSIR) have been developed for marine and terrestrial environments (Elliott, 2002; Holman et al., 2005; La Jeunesse et al., 2003; Odermatt, 2004; Scheren et al., 2004), adopting a causal-chain approach to infer pressure-state relationships between human activities and ecosystem state (Rounsevell et al. 2010). The number of potential links between sectors and the state of the ecosystem (Airoldi and Beck, 2007; Knights et al., 2013) can increase the difficulty of decision-making, especially when time is limited (Haynes, 2009). In support, several frameworks for formal decisionmaking are available (Jeffrey, 1983; Jeffrey, 1992; Resnik, 1987) with risk assessment in particular providing a flexible, problem-solving approach that is capable of linking the relationship between human activities and the environment supporting the decision-making needs of environmental managers (Hope, 2006). Risk assessment in general describes the likelihood and consequences of an event. In the context of EBM, it evaluates the degree to which human activities interfere with the achievement of management objectives that are related to particular ecological characteristics (Samhouri and Levin, 2012) and is increasingly seen as a way to integrate science, policy and management (CENR, 1999).

To date, risk assessment has been used to assess a wide range of environmental issues. Early efforts addressed a single ecosystem component and considered few threats (e.g. Francis, 1992), followed by more comprehensive frameworks that were developed for species (e.g. Kappel, 2005; Samhouri and Levin, 2012) or features (e.g. Zacharias and Gregr, 2005; Halpern et al., 2007). In none of these cases was a specific link to existing environmental policy made. But in perhaps the most extensive framework to date, Driver-Pressure-State combinations for entire ecosystems were developed (Robinson et al. 2013; Knights et al. in press) and these combinations (which were referred to as "impact chains") were explicitly linked to existing policy objectives, namely the Marine Strategy Framework Directive (MSFD) and its qualitative descriptors of good environmental status (GES) (EC, 2008a). Assessing the risk to an ecosystem from a particular impact chain can be done using quantitative approaches (e.g. Francis, 1992; Samhouri and Levin, 2012) or qualitative approaches (e.g. Breen et al., 2012; Fletcher, 2005; Fletcher et al., 2010). Ecological risk assessments (e.g. Fletcher, 2005; Campbell and Gallagher, 2007; Astles et al., 2006) tend to be based on a likelihoodconsequence approach for estimating the risk of a rare or unpredictable event (i.e. calamities) (Williams et al., 2011). However, when an assessment of on-going (current) pressure is needed (i.e., normal operations, where the likelihood equals $100 \%$ ), then an exposure-effect analysis is more suitable (Smith et al., 2007) using qualitative descriptors such as habitat resistance and resilience to assess the vulnerability of habitats (Bax and Williams, 2001) and more recently, assess the potential for EBM at a sub-regional scale (Samhouri and Levin, 2012).

Building on the vulnerability measures of Halpern et al (2007), Robinson et al. (2013) conducted a qualitative pressure assessment that assesses the threat from different driver-pressure combinations to the state of the ecosystem components (thus making up impact chains) for all European regional seas. From this, Knights et al. (in press) used an exposure-effect analysis with five criteria to assess risk for each impact chain which can be interpreted as the likelihood or degree to which human activities interfere with the achievement of policy objectives. Risk can then be assessed for each Driver, Pressure or State component through aggregation across those impact chains that include that particular Driver, Pressure or State component. This, in turn, allows for an evaluation of how risk will decrease over time once management on one or more of these components or combinations of components is implemented.

The logical next step towards achieving policy objectives is the choice of appropriate ecosystem-based management (EBM) measures to mitigate those risks affecting these objectives (Samhouri and Levin, 2012). To that end we developed a comprehensive framework for integrated Management Strategy Evaluations (iMSE) framework that links directly to the risk assessment approach described (e.g. 
Halpern et al., 2007; Knights et al., in press), providing guidance for the identification and selection of consistently defined measures, and also allowing an evaluation of the effectiveness of these measures through their reduction of risk. For this, the effectiveness of a management measure depends on both (a) the number of impact chain(s) it targets; (b) the weighting of the chains based on the five risk criteria; and (c) the likelihood the measure can reduce the impact of these chains. Measures that target a selection of impact chains that together contribute a high proportion of the risk to the ecosystem being assessed are likely to be most effective.

\section{Material and methods}

\subsection{Summary of risk assessment approach}

This framework for the identification, selection and evaluation of management measures (MMs) is based on the most extensive risk assessment approach to date consisting of Driver-Pressure-State combinations (so-called "impact chains") that each contribute to the risk of not achieving policy objectives (Knights et al., in press). Risk is determined based on scores given to five criteria. These are: (1) the spatial (Extent), and (2) temporal (Frequency) overlap of a sector-pressure and ecological characteristic, which together describe the exposure of the ecological component to a sector-pressure combination in terms of their spatio-temporal overlap; (3) the Degree of Impact (DoI) of the sectorpressure on that characteristic describing the severity of the impact where interactions occur; whilst the potential for recovery after the impact has occurred is described by (4) the Persistence of the pressure (the number of years before the pressure impact ceases following cessation of the activity introducing it), and (5) the Resilience of the ecological characteristic (recovery time in years) (see full details of criteria in Robinson et al., 2013). Based on these criteria, Knights et al. (in press) allocated scores and considered two aspects of risk:

- $\quad$ Impact Risk $(I R)=$ the likelihood of an adverse ecological impact following a sector-pressure introduction $=$ Extent $*$ Frequency $*$ DoI

- Recovery Lag $(\mathrm{RL})=$ the time it takes for an impacted ecological component to return to preimpacted condition after the implementation of a measure $=$ Persistence $*$ Resilience.

\section{$2.2 \quad$ Selection of MMs}

As MMs tend to either reduce the exposure to a pressure, the severity of impacts where there are interactions, or actively promote recovery, it is possible to select measures using the five criteria described above, and thus to target particular aspects of risk in the ecosystem (Table 1). Linked to these risk assessment criteria, the selection of MMs can then also be guided by two distinct aspects of a MM: the "Focus" and the "Type" of measure. The "Focus" is determined by the element(s) of the impact chain (i.e. Driver-Pressure-State) that the measure targets. A measure may involve only one single element in the impact chain (i.e. Driver, Pressure or State), the combination of two (i.e. DriverPressure or Pressure-State), or all three making the measure more specific as more elements are combined (see first column in Table 1 and examples in Table 2). The "Type" distinguishes six categories, loosely based on the measures distinguished in (EC, 2008b), that mitigate or counteract the impact of the human activity on the ecosystem directly. Each category links specifically to one of the risk criteria (Table 1).

Table 1. A typology for ecosystem-based management measures based on the impact-chain "Focus" and control "Type" of a measure distinguishing three groups of generic measures: affecting several impact chains and either exclusively reduce impact risk (red); reduce recovery lag (green); or reduce both impact risk and recovery lag (yellow). White cells indicate no possible combination of "Focus" and "Type". The numbers in the cells correspond to the management measures in Table 2. 


\begin{tabular}{|c|c|c|c|c|c|c|}
\hline \multirow[b]{2}{*}{ Focus } & \multicolumn{6}{|c|}{ Type } \\
\hline & $\begin{array}{c}\text { Spatial } \\
\text { distribution } \\
\text { controls } \\
\end{array}$ & $\begin{array}{c}\text { Temporal } \\
\text { distribution } \\
\text { controls } \\
\end{array}$ & $\begin{array}{c}\text { Input } \\
\text { control }\end{array}$ & $\begin{array}{l}\text { Output } \\
\text { control }\end{array}$ & Remediation & Restoration \\
\hline D & \multicolumn{2}{|c|}{1,2} & 6 & & & \\
\hline D-P & \multicolumn{2}{|c|}{3} & & 7,8 & 13 & \\
\hline $\mathbf{P}$ & \multicolumn{2}{|c|}{4} & & 9 & 14 & \\
\hline P-S & \multicolumn{2}{|c|}{4} & & 10 & 15 & \\
\hline $\mathbf{S}$ & \multicolumn{2}{|c|}{5} & & & & $17,18,19$ \\
\hline D-P-S & & & & 11,12 & 16 & 20 \\
\hline $\begin{array}{c}\text { Risk } \\
\text { assessment } \\
\text { criteria }\end{array}$ & Extent & Frequency & \multicolumn{2}{|c|}{ Degree of Impact } & Persistence & Resilience \\
\hline $\begin{array}{l}\text { Aspects of } \\
\text { risk }\end{array}$ & \multicolumn{4}{|c|}{ Impact Risk } & \multicolumn{2}{|c|}{ Recovery Lag } \\
\hline \multirow{2}{*}{ Time horizon } & \multicolumn{4}{|c|}{ Present } & \multicolumn{2}{|c|}{ Past } \\
\hline & \multicolumn{6}{|c|}{ Future } \\
\hline
\end{tabular}

The measure types "Spatial distribution controls", "Temporal distribution controls", "Input control" and "Output control" each (or in combination) mitigate or counteract aspects of Impact Risk. The first two involve a reduction of the extent in space and time of the activity and are further considered as a single type, i.e. Spatio-temporal distribution controls, because in addition to spatially closed areas, e.g. Marine Protected Areas (MPAs) (Browman and Stergiou, 2004), or seasonal closures (Dinmore et al., 2003) there are Real Time Closures (RTCs) (Bailey et al., 2010) which are essentially a combination of both. The latter two come originally from fisheries management and affect the DoI where "input control" applies to capacity (size of the fleet) or effort (fishing activity), and "output control" applies to the reduction of the catch itself (FAO, 2003). In this integrated framework, i.e. beyond fisheries management, we interpreted input controls as only mitigating the Driver while output controls mitigate the Pressure, possibly in combination with either some Driver or some State component. While the four types of controls (i.e. spatial distribution, temporal distribution, and input/ output control) mitigate the risk of potential impact (respectively linked to assessment criteria: Extent, Frequency and DoI), the mitigation of any already existing impacts occurs through the reduction of the Recovery Lag, for which we distinguish between the reduction of pressure persistence through "Remediation" measures, and the increase of the resilience of the state component(s) through "Restoration" measures.

\subsection{Evaluating effectiveness of MMs}

For the evaluation of the effectiveness of MMs, a non-exhaustive list of examples of MMs was compiled (Table 2) that could reduce risk through the various pathways indicated in Table 1 . The process of identification and selection of possible MMs was based on three groupings of measures (see colours in Table 1) distinguishing between fairly generic measures (several impact chains) and very specific measures (involving few impact chains), and either aimed at the reduction of Impact Risk or Recovery Lag. The aim was to select examples that together covered most of the boxes shown in Table 1, so that the utility of the approach in evaluating effectiveness could be explored fully.

For the evaluation of the effectiveness of measures we assumed a full implementation of the measure (i.e. a $100 \%$ reduction of the risk criteria linked to the type of measure). For example, if the MM covered a ban on littering (not specified to any sector), then any impact chain that contained Marine Litter as pressure would be removed and the reduction in risk (across the whole ecosystem) associated with this is calculated to express the effectiveness of the MM. Using the two different risk aspects mentioned earlier, i.e. Impact Risk and Recovery Lag, we considered it relevant to assess the effectiveness of MMs against three time horizons:

- "Past" - aimed at recovery of already affected ecosystems as reflected by the Recovery Lag (RL) score, 
- "Present" - aimed at reducing the likelihood of an adverse ecological impact from current activities as reflected by the Impact Risk (IR) score, while

- "Future" - aimed at reducing the likelihood of impacts, specifically those that require a long time to recover from. This is reflected by Total Risk (TR) which is the product of RL and IR.

These "Time Horizon" perspectives were used in the process of identification and selection of possible management measures, as well as the subsequent evaluation of these measures.

\section{Results}

The results show (1) the application of our framework incorporating the European risk assessment data to guide the identification and selection of MMs for the North East Atlantic (NEA) region, followed by (2) an evaluation of the effectiveness of measures in reducing risk to the ecosystem across three management time horizons.

\subsection{Identification and selection of MMs}

The identification and selection of MMs was approached differently for each of the three (color coded) groups of generic measures identified using the typology in Table 1. As the type of measures intended to mitigate the IR mostly involve a focus on Driver and/or Pressure, the selection of these measures can be guided by information such as represented in Figure 1. This shows that for the NEA, fishing is by far the most important driver (37\% across all pressures), and selective extraction of species (33\% across all drivers) the main pressure, the combination contributing $26 \%$ to IR, making these the most likely candidates (separately or in combination) for MMs aimed at mitigating IR. Other important drivers are shipping (11\%) and tourism/recreation (9\%) while marine litter and the introduction of synthetics are the next important pressures each contributing $11 \%$ to IR.

The type of measures intended to reduce the RL mostly involve a focus on Pressure and/or State (see Table 1, Figure 2). The four least resilient ecosystem components, i.e. both demersal and pelagic fish, marine mammals, and seabirds contribute to $88 \%$ (across all pressures) of the RL while the five most persistent pressures, i.e. sealing, marine litter, introduction of synthetics, introduction of nonsynthetics, introduction of radionuclides, contribute to $81 \%$ (across all components) of the RL. For more specific measures (i.e. focus on P-S rather than $\mathrm{P}$ or $\mathrm{S}$ ) any combination of these pressures and ecosystem components can be considered. Each combination contributes to approximately $3-4 \%$ of the RL.

The third group to guide the identification and selection of measures involves very specific measures (i.e. focus on specific D-P-S combination), which depending on the choice of the type of management measures, may reduce the IR (i.e. any of the control types), RL (i.e. Remediation, Restoration) or TR (all control types). When individual impact chains are ordered according to their contribution to the overall IR, RL or TR (Figure 3) we find that notably for IR and TR there are a few, but different, individual impact chains that contribute disproportionately (i.e. furthest to the left with a relative contribution to risk $>1$ ), and thus should be targeted by specific management measures. For IR, it is fishing affecting demersal, pelagic and deep sea fish as well as the sublittoral sediment habitat through the pressure biological extraction. These four individual chains together contribute more than $22 \%$ to the total IR. In contrast, for TR marine litter from shipping affecting the least resilient ecosystem components (i.e. seabirds, marine mammals and fish) emerges as the main contributors causing close to $10 \%$ of the TR. The driver coastal infrastructure is affecting the littoral habitats (both sediment and rock) through sealing as well as some other pressures. The pressure marine litter is caused mainly by shipping and fisheries and affects all ecosystem components. 


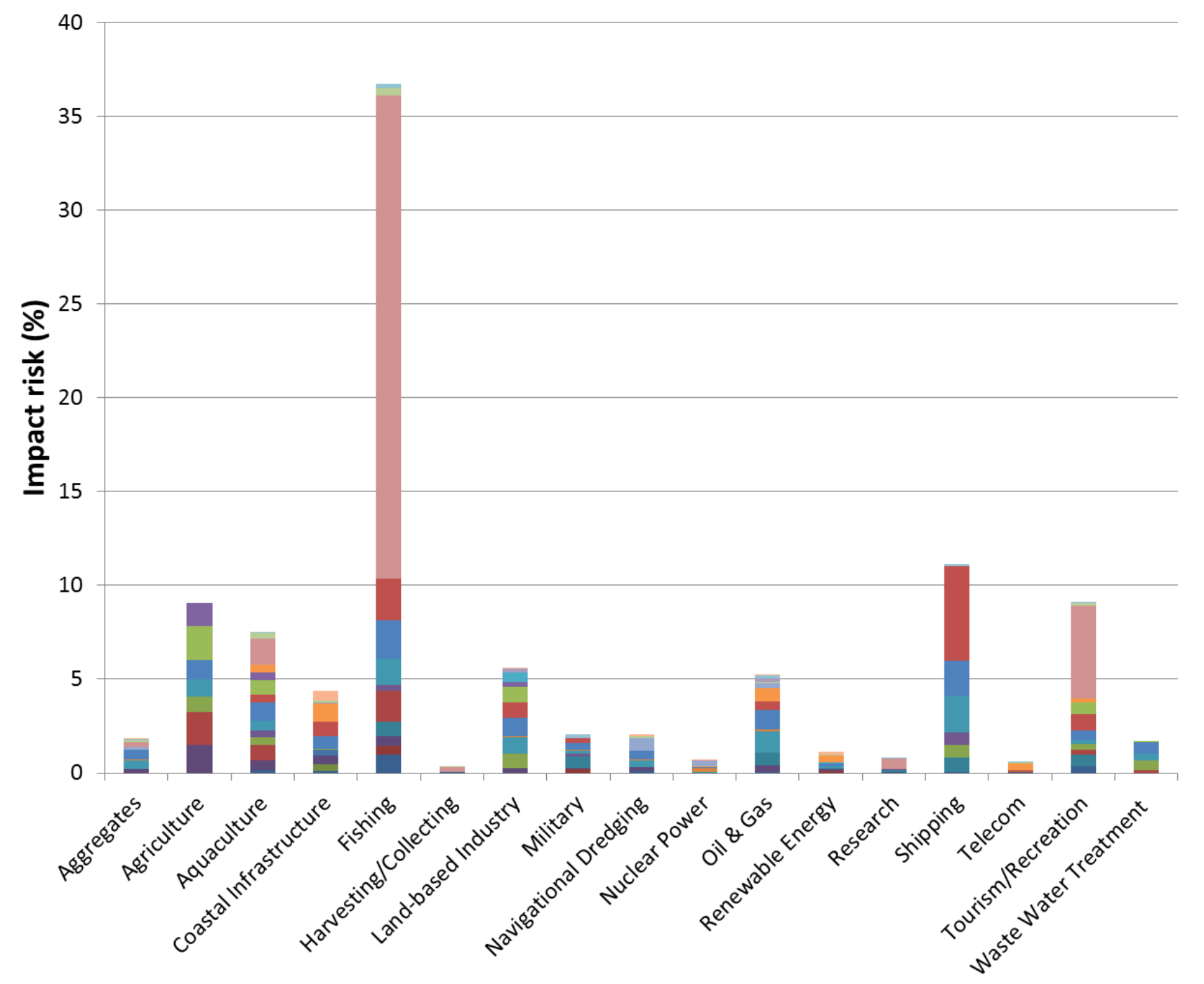

Water flow rate changes

- Underwater noise

- Thermal Changes

Smothering

- Selective extraction of species

- Selective Extraction of Non-living material

Sealing

- Salinity Changes

- $\mathrm{pH}$ changes

$\square \mathrm{N}$ and $\mathrm{P}$ enrichment

- Marine Litter

- Introduction of Synthetics

- Introduction of Radionuclides

a Introduction of Non-synthetics

- Introduction of NIS

- Introduction of microbial pathogens

- Input of organic matter

- Emergence regime change

n Electromagnetic changes

- Death or injury by collision

- Changes in Siltation

Figure 1. Impact Risk per Driver-Pressure combination expressed as the \% contribution to the total risk of an adverse impact. 


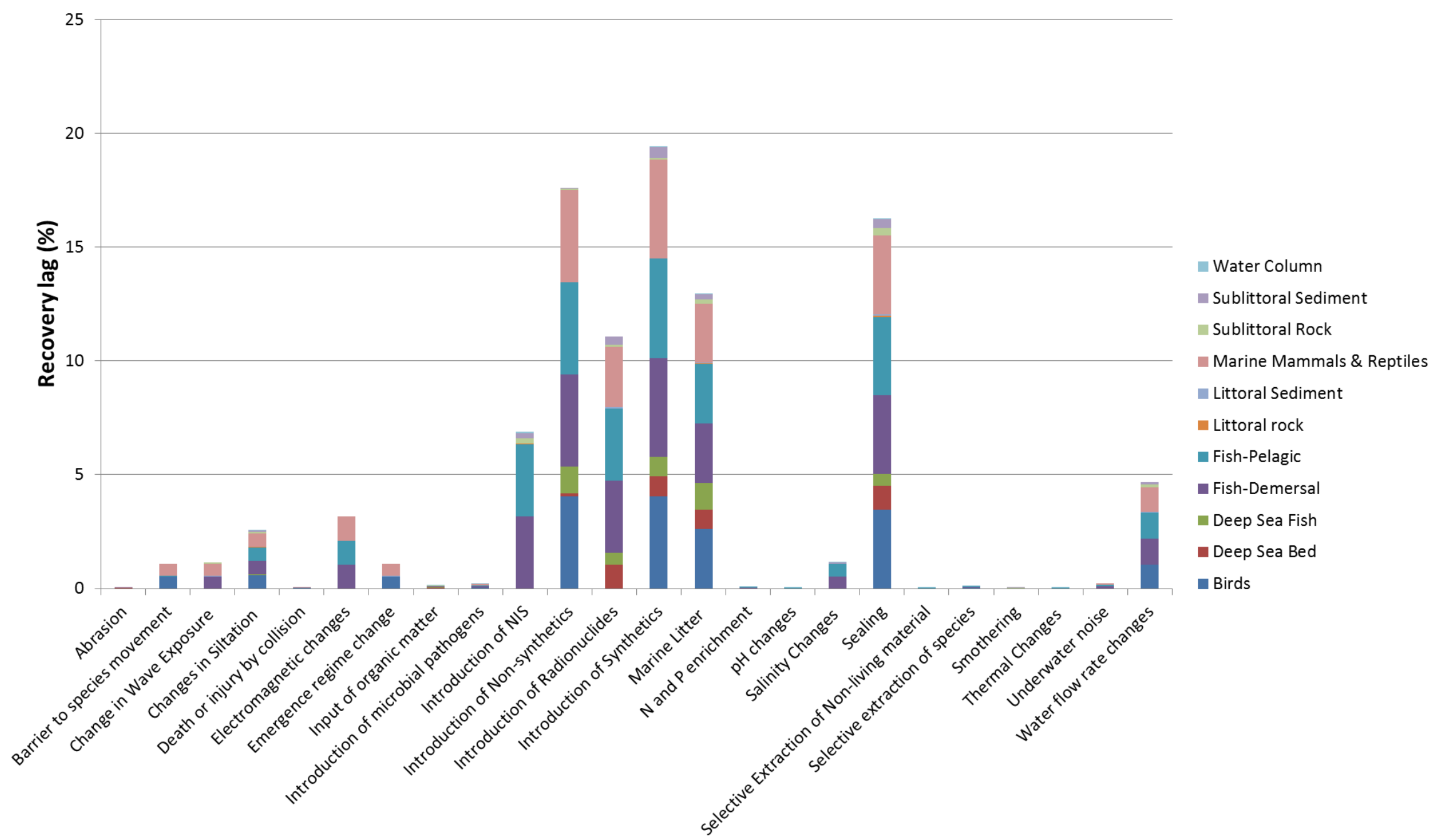

Figure 2. Recovery Lag per Pressure - State combination expressed as the \% contribution to the total time it takes for the impacted ecological components to return to pre-impacted condition after the introduction of the pressures has stopped. 


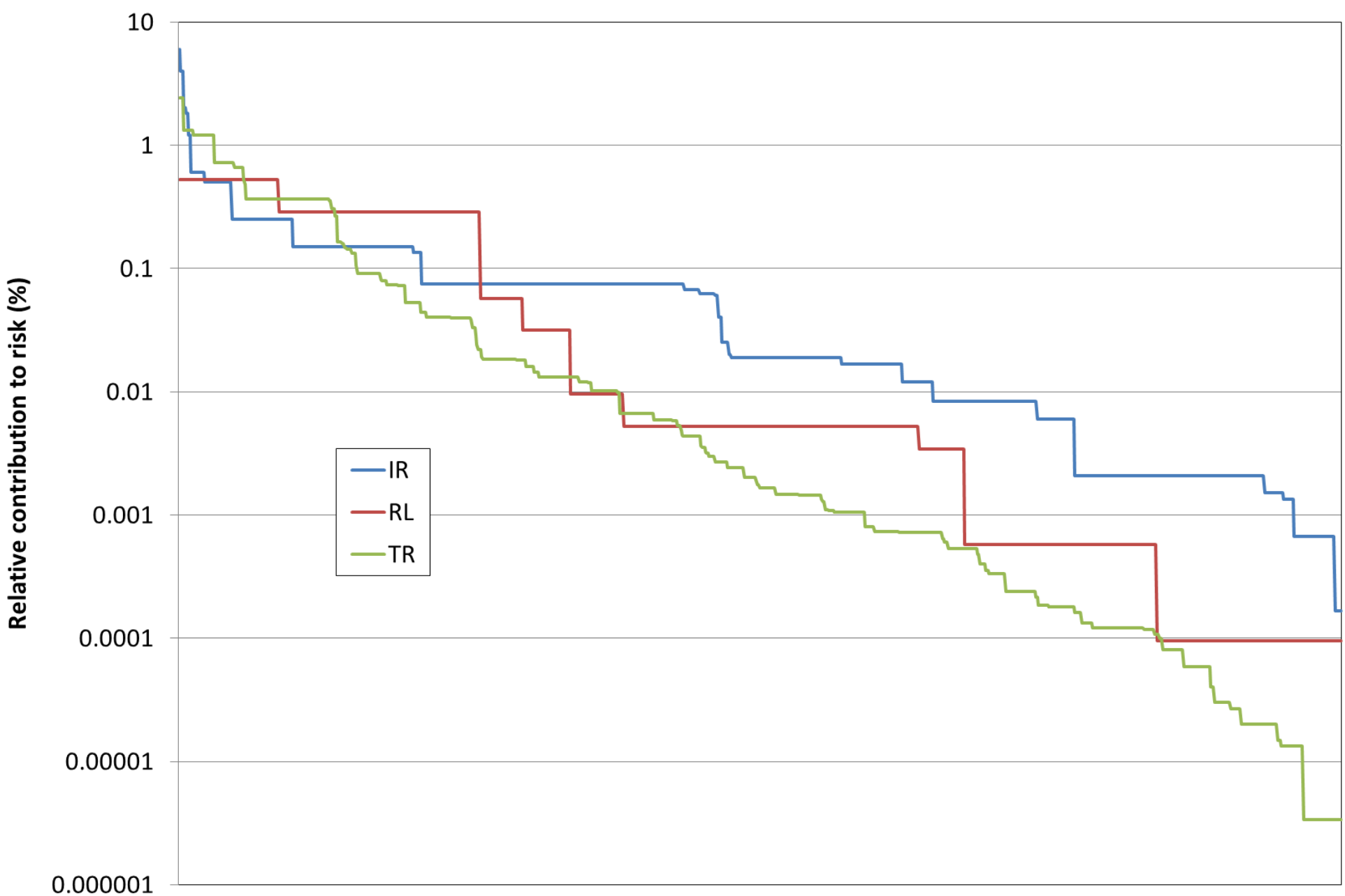

Individual impact chains in decreasing order

Figure 3. Relative contribution to Total Risk (TR) and the two aspects (IR=Impact Risk, RP=Recovery Potential) that determine TR by each individual impact chain arranged in decreasing order. Note the logarithmic scale of the y-axis. 


\subsection{Effectiveness of MMs at reducing risk over three time horizons}

Guided by the above results, we selected a non-exhaustive suite of 20 potential management measures (Table 2) and calculated the reduction in IR, RL and TR the full implementation of these measures would achieve. We phrased the measures 1-3 as "Spatio-temporal closures/restrictions...." in line with our assertion that often measures contain both spatial and temporal dimensions. In this assessment MMs 1 and 2 are conventional fisheries management measures but here considered in an EBM context where not only more pressures are considered than the commonly used "biological extraction of species" (i.e. catch) but also other components of ecosystem state than fish. The distinction between MMs 1 and 2 lies not only in the subset of fish they target (i.e. respectively pelagic versus demersal) but also in that the demersal fishery impacts the seafloor habitats through physical disturbance (i.e. abrasion, smothering and changes in siltation). Other pressures, such as marine litter and underwater noise apply to both fisheries. Because the MMs 1 and 2 are assumed to involve a spatio-temporal closure for the fishing vessels belonging to a specific metier (i.e. demersal or pelagic), we consider these MMs as focussed on the Driver only. However, in Table 2 we used the selection of the State components, pelagic fish and demersal fish, to focus on the appropriate fishing metiers.

MMs 4 and 5 are explicitly spatial but this should not imply that measures with also a temporal component can be conceived for those cells in table 1. No Take zones, or totally closed areas (Horwood et al., 1998), can be defined as marine areas in which the extraction of living and non-living resources is permanently prohibited, except as necessary for monitoring or research to evaluate effectiveness (NRC, 2001, cited by Jones, 2006). Although this measure can be introduced to reduce the risk for a specific ecosystem component (Focus $=$ P-S), it could also be introduced to protect all components in that area (Focus $=\mathrm{P}$ ). Based on this definition, the measure affects all impact chains that include the pressures 'selective extraction of non-living resources' or 'selective extraction of species'; and are not related to the driver 'research'. Although in some cases the focus could include specific components of State, all ecosystem components were included in this assessment.

MMs 8, 9 and 13-15 all involve marine litter but the \% risk reduction achieved varies considerably because of the difference in focus of the measures. MM 9 is the least specific and therefore results in the largest potential reduction. Even though MM 8 and MM 13 both involve the mitigation of effects of marine litter from fisheries we distinguished between MM 8 which involves all litter and MM 13 mitigating only the effects of "ghost-fishing", here assumed to affect fish only. MM 14 will only remove marine litter from fishable habitats while MM 15 was assumed to affect only the littoral habitats and the ecosystem components that inhabit the intertidal zone.

Table 2 shows that management measures cause different reductions in the three aspects of risk which correspond to the three time horizons for management we considered. From a "Present" perspective,

Table 2. Non-exhaustive list of potential management measures, how these were interpreted in terms of "Focus", the number of impact chains affected based on this "Focus" and the maximum potential reduction that can be achieved if the measures are fully implemented and effective. The numbers correspond to those in Table 1. RL=Recovery Lag, IR=Impact Risk and $\mathrm{TR}=$ Total Risk.

\begin{tabular}{|c|c|c|c|c|c|c|}
\hline \multirow{2}{*}{ Nr. } & \multirow{2}{*}{ Management measure } & \multirow{2}{*}{ Focus } & \multirow{2}{*}{$\begin{array}{l}\text { Number } \\
\text { Impact } \\
\text { Chains }\end{array}$} & \multicolumn{3}{|c|}{$\begin{array}{c}\text { Potential reduction } \\
(\%)\end{array}$} \\
\hline & & & & RL & IR & TR \\
\hline 1 & $\begin{array}{l}\text { Spatio-temporal closures of } \\
\text { the pelagic fishery }\end{array}$ & $\begin{array}{l}\mathrm{D} \text { (Fisheries) } \\
\mathrm{P} \text { (All pressures except those disturbing } \\
\text { the seabed) } \\
\mathrm{S} \text { (Excluding demersal and deep sea fish } \\
\text { and all seafloor habitats) }\end{array}$ & 27 & 0 & 11 & 9 \\
\hline 2 & $\begin{array}{l}\text { Spatio-temporal closures of } \\
\text { the demersal fishery }\end{array}$ & $\begin{array}{l}\text { D (Fisheries) } \\
\text { P (All pressures specifically related to } \\
\text { this type of fishery) } \\
\text { S (Excluding pelagic and deep sea fish } \\
\text { but including all habitats) }\end{array}$ & 52 & 0 & 25 & 9 \\
\hline 3 & $\begin{array}{l}\text { Spatio-temporal restrictions } \\
\text { to the discharge of ballast } \\
\text { water }\end{array}$ & $\begin{array}{l}\text { D (Shipping, Military) } \\
\text { P (Non-indigenous species) }\end{array}$ & 4 & 0 & 1 & 3 \\
\hline 4 & No take zone(s) & $\mathrm{P}$ (Selective extraction of species and & 46 & 0 & 34 & 2 \\
\hline
\end{tabular}




\begin{tabular}{|c|c|c|c|c|c|c|}
\hline & & $\begin{array}{l}\text { non-living resources) } \\
\mathrm{S} \text { (may be applied, e.g. a specific seafloor } \\
\text { habitat but was not in this assessment) }\end{array}$ & & & & \\
\hline 5 & $\begin{array}{l}\text { Closed areas for deepwater } \\
\text { coral or seamounts }\end{array}$ & S (Deep sea bed) & 28 & 0 & 3 & 6 \\
\hline 6 & $\begin{array}{l}\text { Decommissioning fishing } \\
\text { vessels }\end{array}$ & D (Fisheries) & 76 & 0 & 37 & 18 \\
\hline 7 & $\begin{array}{l}\text { System for identification of } \\
\text { oil spills from offshore } \\
\text { installations }\end{array}$ & $\begin{array}{l}\text { D (Oil \& Gas) } \\
\text { P (Non-synthetic compounds) }\end{array}$ & 10 & 0 & 1 & 2 \\
\hline 8 & Biodegradable fishing gear & $\begin{array}{l}\mathrm{D} \text { (Fisheries) } \\
\mathrm{P} \text { (Marine Litter) }\end{array}$ & 11 & 0 & 2 & 6 \\
\hline 9 & Ban on littering & P (Marine Litter) & 76 & 0 & 11 & 27 \\
\hline 10 & Fish guide & $\begin{array}{l}\text { P (Selective extraction of species) } \\
\text { S (Fish) }\end{array}$ & 11 & 0 & 19 & 2 \\
\hline 11 & MSC & $\begin{array}{l}\mathrm{D} \text { (Fisheries) } \\
\mathrm{P} \text { (Selective extraction of species) }\end{array}$ & 10 & 0 & 26 & 2 \\
\hline 12 & TAC/Quota & $\begin{array}{l}\mathrm{D} \text { (Fisheries) } \\
\mathrm{P} \text { (Selective extraction of species) } \\
\mathrm{S} \text { (Fish) }\end{array}$ & 3 & 0 & 14 & 1 \\
\hline 13 & $\begin{array}{l}\text { Retrieval of lost or } \\
\text { abandoned fishing gear }\end{array}$ & $\begin{array}{l}\text { D (Fisheries) } \\
\text { P (Marine Litter) } \\
\text { S (Fish) }\end{array}$ & 3 & 1 & 0 & 4 \\
\hline 14 & $\begin{array}{l}\text { Collection of fished litter } \\
\text { (fishing for litter scheme) }\end{array}$ & $\begin{array}{l}\text { P (Marine Litter) } \\
\text { S (Sub-littoral habitats and water } \\
\text { column) }\end{array}$ & 21 & 0 & 0 & 1 \\
\hline 15 & Additional beach cleaning & $\begin{array}{l}\text { P (Marine Litter) } \\
\text { S (Seabirds, Mammals, Littoral habitats) }\end{array}$ & 30 & 5 & 0 & 9 \\
\hline 16 & $\begin{array}{l}\text { Cleaning pollution from } \\
\text { offshore drilling operations, } \\
\text { e.g. drilling muds and } \\
\text { cuttings }\end{array}$ & $\begin{array}{l}\text { D (Oil \& Gas) } \\
\text { P (Synthetic and Non-synthetic } \\
\text { compounds) } \\
\text { S (Excluding deep sea) }\end{array}$ & 17 & 2 & 0 & 3 \\
\hline 17 & Breeding program Seabirds & S (Seabirds) & 79 & 17 & 0 & 12 \\
\hline 18 & Breeding program Fish & S (Demersal fish) & 130 & 25 & 0 & 29 \\
\hline 19 & $\begin{array}{l}\text { Breeding program Marine } \\
\text { mammals }\end{array}$ & $\mathrm{S}$ (Marine mammals) & 110 & 22 & 0 & 16 \\
\hline 20 & $\begin{array}{l}\text { Optimise shape burrow pits } \\
\text { for ecological development }\end{array}$ & $\begin{array}{l}\text { D (Aggregates) } \\
\text { P (Abrasion, Selective extraction of non- } \\
\text { living resources) } \\
\text { S (Sediment habitats but not deep sea) }\end{array}$ & 4 & 0 & 0 & 0 \\
\hline
\end{tabular}

we only consider measures that affect the likelihood of current activities to cause an adverse impact (MMs 1-12 where RL is not affected) and do not consider the remaining management measures (MMs 13-20 where IR is not affected), which are specifically intended to reduce existing adverse impacts and hence only relevant for the "Past" perspective. All management measures are relevant for the "Future" perspective for which TR applies.

The "Past" perspective (RL column in Table 2) shows that the most effective (and very generic) Restoration measure (MM 18) targeting the most impacted ecosystem component (i.e. demersal fish) performs better in terms of a reduction of the RL than the best (and relatively specific) Remediation measure (MM 15) targeting the $4^{\text {th }}$ important pressure (i.e. Marine litter).

The "Present" perspective (IR column in Table 2) shows that measures targeting what is currently the main driver causing adverse impacts (i.e. fisheries) either through a Spatio-temporal closure (MM 2), Input control (MM 6) or Output Control (MM11) cause the largest reductions in IR and that there is only a weak relationship between the performance of the measures and the number of impact chains targeted by the measure. 
The "Future" perspective (TR column in Table 2) shows that an Output control (MM 9) on a relatively persistent pressure (i.e. marine litter) performs almost equally well as a very extensive Restoration measure (MM 18) on a fairly resilient ecosystem component affected by many different drivers.

\section{Discussion}

This framework shows how EBM can be developed for the NEA based on the type of risk assessments available for this region as well as the other European MSFD regions. The results illustrate two phases in the EBM process: 1) identification/selection and 2) evaluation of management measures.

Table 1 combined with Figures 1-3 are mostly relevant for the first phase where the table helps to identify the measures while the figures are examples of how the information from the risk assessment can be used to select potential measures. Following the three "Time Horizon" perspectives, the figures revealed that the main adverse impacts from "Past" activities come from persistent pressures such as the introduction of (non-)synthetics, radionuclides or non-indigenous species, marine litter and sealing. A "Present" management perspective would focus on the potentially large adverse impacts of current fishing practices which, however, can be mitigated in the relatively short term. A "Future" perspective could focus the decision-makers on a few impact chains involving widespread activities such as shipping or fishing causing persistent pressures (e.g. marine litter or non-indigenous species) that affect ecosystem components that require long recovery times (e.g. marine mammals, birds) which are likely to cause persistent adverse impacts with high likelihood.

For the second phase where the management measures were evaluated, we assumed the measure to be $100 \%$ effective (i.e. full implementation and compliance) of each measure, e.g. spatial distribution control aimed at a specific driver effectively results in a closure of $100 \%$ of the area covered by that driver thereby effectively reducing the likelihood of any impact through all relevant impact chains of that driver to 0 . Similarly we assumed that restoration of a specific ecosystem component resulted in the complete recovery to pre-impact levels of that ecosystem component. While we acknowledge that in reality it is probably not feasible to ever achieve such goals, it is considered appropriate for the purpose of this exercise because $100 \%$ effectiveness results in higher reductions (i.e. ten-fold compared to a more realistic $10 \%$ effectiveness) while giving the same relative performance of the measures, both qualitatively (i.e. the same measure will always come out best) as well as quantitatively (i.e. the degree to which one measure outperforms the other).

The evaluation of the management measures can be based on both a qualitative (i.e. based on ranked order) and quantitative (based on \% potential reduction of risk) perspective of the relative performance of the measures but there are several reasons why this framework should only be used for a qualitative evaluation. Firstly, even though TR and its two aspects (IR and RL) are based on criteria that represent real-world characteristics, the way these characteristics are assessed (Robinson et al., 2013) and how subsequently the achieved reduction in the criteria and thus (aspects of) risk are calculated prevent any simple (i.e. linear) relationship to real-world characteristics of anthropogenic pressure (e.g. fishing intensity, or quantity of some contaminant) or ecosystem state (e.g. the abundance of a species or quality of a habitat) that would determine the true relative performance of these measures. Secondly, ultimately the selection of management measures is not only based on their performance to improve ecosystem state but also on various socio-economic considerations. These determine the potential reduction the measure can achieve as well as the likelihood this is actually achieved. In this framework, a reduction in any of the criteria that determine IR, RL and thus TR would give the same reduction in that aspect of risk and can therefore be implemented interchangeably. In this framework it makes no difference if a Temporal distribution- (Reducing Extent), Spatial distribution- (Reducing Frequency), Input- or Output control (Reducing DoI) is implemented as they all reduce IR (of those impact chains targeted by the Focus-part of the measure) with the same level of effectiveness. Similarly for Remediation and Restoration in relation to RL. In reality, however, the selection of a measure, determined by "Type" and "Focus", will be mostly decided based on socio-economic and institutional considerations (Knights et al. 2014) resulting in a very different level of effectiveness for each of those criteria (linked to "Type") and thus different reductions of IR, RL or TR. 
In this framework the "Type" only determines which aspect of TR (i.e. IR or RL) is reduced and the to (aspects of) risk through the observed relationship between the number of impact chains targeted and the reduction of (those aspects of) risk.

While each measure "Type" is directly linked to a risk assessment criterion such that it is obvious how the implementation of the measure reduces the criterion (e.g. Spatial distribution controls reduce the Extent of the overlap), this is less clear for the Input/Output control measures linked to the DoI. While in reality the Input/Output control directly relates to the intensity or amount of the activity causing the pressure, this is not the case in our framework because intensity is not considered in the definition of DoI (i.e. severity of a single interaction event between the pressure and an ecosystem component, Robinson et al., 2013). In fisheries management, for example, this implies some output control, e.g. technical measure, could reduce the DoI (e.g. from acute to chronic, see Robinson et al., 2013) but others, e.g. Total Allowable Catch (TAC), cannot as it only affects the intensity of the pressure. For this evaluation we assumed any output control would reduce the DoI but the suitability of this framework to evaluate input/output control measures would improve if the intensity or amount of (the activity causing the) pressure was explicitly included in the assessment of severity.

The "Type" of measures in this paper include several measures that occur in the MSFD Annex VI Programmes of Measures, namely "Input controls", "Output controls", "Spatial and temporal distribution controls" and "Mitigation and remediation tools", where the latter MSFD measure includes both our restoration and remediation measures. The other potential MSFD measures, i.e. "Management coordination measures", "Measures to improve the traceability", "Economic incentives", "Communication, stakeholder involvement and raising public awareness", are essentially indirect measures that affect our proposed, direct, measures through some (implementation) mechanism and are therefore not explicitly considered in this framework.

In order to include all the measures occurring in the MSFD Annex VI Programmes of Measures, we can expand our framework into a hierarchy based on existing typologies of measures (ARCADIS, 2012; van Vliet, 1999) that distinguishes between physical measures (identical to our five "Types"), which may be carried out by any stakeholder (i.e. industry, NGO, policy) and three types of instruments that are implemented at a governmental level and may initiate these physical measures.

These three types of instruments, i.e. regulatory, economic and social, thus have an indirect effect on the impact chain insofar as respectively institutional, market-based, or participatory aspects are involved.

Regulatory instruments emerge from the principle that human nature is self-centered/egoistic and should be controlled by the government (van Vliet, 1999). These instruments directly influence the behavior of actors by imposing rules that limit or prescribe the actions of the target group (ARCADIS, 2012). Irrespective of the management mechanism employed, all instruments are built on a common legal basis and require enforcement and control if they are to be successful.

Economic instruments may also be used. Their effectiveness is based on the principle that the pursuit of individual economic self-interest will lead to the optimal benefit for everyone (van Vliet, 1999). These instruments are defined by the OECD as "fiscal and other economic incentives and disincentives to incorporate environmental costs and benefits into the budgets of households and enterprises" (UN, 1997). The common underlying rationale is inspired by the polluter-pays principle (UN, 1997) and involves a modification of the actors' behavior through the price of a commodity in the market such that acceptable levels of pollution, optimum rates of resource use or depletion are achieved and thus the protection of the environment is ensured. Examples of such instruments are feebased systems, subsidies, liability and compensation regimes and trading systems (ARCADIS, 2012). A key feature of social instruments is the participatory nature and the essence of legitimacy lies in the involvement of stakeholders in decision-making, thereby improving the knowledge system on which policy making is based and possibly leading to higher compliance rates (van Vliet, 1999). Sectors are stimulated to take actions based upon their own motivation, often through information (education, training) or awareness raising campaigns. Good or bad image building and associated perception from 
society (e.g. through communication or certification) can provide important incentives to adapt behavior.

Some of the measures considered in our framework do not require the implementation of any instrument by regional managers to initiate change. For example, many sectors are often in the process of continuous development and application of new technologies (i.e. technical measures for output control). In addition there are voluntary initiatives of private stakeholders, which can initiate community action (i.e. remediation measures).

This typology of MMs was developed to help implement the MSFD (EC, 2008a) and together with our framework could contribute to EBM as it merges the three pillars of sustainability, i.e. environmental, economic and social (UN, 2005) with the institutional context. While the framework developed in this study assesses the performance of the potential MMs in terms of their reduction of the risk of an adverse ecological impact, and the time it takes to return to pre-impacted conditions after the implementation of the $\mathrm{MM}$, the final choice of the actual MMs requires an interpretation of the feasibility of the guidance coming from this type of framework in a real-world context. The instruments to initiate them should be based on the outcome of this process considered in the appropriate institutional and socio-economic context.

\section{Acknowledgements}

This study was funded by the EU FP7 programme 'Options for Delivering Ecosystem-based Marine Management' (ODEMM; grant number 244273; www.liv.ac.uk/odemm).

\section{References}

Airoldi, L., and Beck, M. W. 2007. Loss, status and trends for coastal marine habitats of Europe. Oceanography and Marine Biology, Vol 45, 45: 345-405.

ARCADIS. 2012. Economic assessment of policy measures for the implementation of the Marine Strategy Framework Directive. pp. 160 pp.

Astles, K. L., Holloway, M. G., Steffe, A., Green, M., Ganassin, C., and Gibbs, P. J. 2006. An ecological method for qualitative risk assessment and its use in the management of fisheries in New South Wales, Australia. Fisheries Research, 82: 290-303.

Bailey, N., Campbell, N., Holmes, S., Needle, C., and Wright, P. 2010. Real Time Closures of Fisheries. 50 pp.

Bax, N. J., and Williams, A. 2001. Seabed habitat on the south-eastern Australian continental shelf: context, vulnerability and monitoring. Marine and Freshwater Research, 52: 491-512.

Bottrill, M. C., Joseph, L. N., Carwardine, J., Bode, M., Cook, C. N., Game, E. T., Grantham, H., et al. 2008. Is conservation triage just smart decision making? Trends in Ecology \& Evolution, 23: 649-654.

Breen, P., Robinson, L. A., Rogers, S. I., Knights, A. M., Piet, G., Churlova, T., Margonski, P., et al. 2012. An environmental assessment of risk in achieving good environmental status to support regional prioritisation of management in Europe. Marine Policy, doi: 10.1016/j.marpol.2012.02.003.

Browman, H. I., and Stergiou, K. I. 2004. Marine Protected Areas as a central element of ecosystem-based management: defining their location, size and number. Marine Ecology-Progress Series, 274: 271-272.

Campbell, M. L., and Gallagher, C. 2007. Assessing the relative effects of fishing on the New Zealand marine environment through risk analysis. ICES Journal of Marine Science, 64: 256-270.

Carroll C, Detloff K, Kinsey S, Nilsson P, Sheavly S, Svärd B, Veiga J, Morison S, Katsanevakis $\mathrm{S}$, 
CBD (2010): Decision adopted by the conference of the parties to the Convention on Biological Diversity at its tenth meeting. X/2. The Strategic Plan for Biodiversity 2011-2020 and the Aichi Biodiversity Targets. Conference of the parties to the Convention on Biological Diversity, Tenth meeting, Nagoya, Japan, 18-29 October 2010, Agenda item 4.4, UNEP/CBD/COP/DEC/X/2, 29 October 2010.

CEC 2002. Council Regulation 2371/2002 of 20 December 2002 on the conservation and sustainable exploitation of fisheries under the Common Fisheries Policy. . OJ L 358/59 31.12.2202.

CENR. 1999. Ecological risk assessment in the federal government. CENR/5-99/001. Committee on Environment and Natural Resources, National Science and Technology Council, Washington, DC, USA.

Dinmore, T. A., Duplisea, D. E., Rackham, B. D., Maxwell, D. L., and Jennings, S. 2003. Impact of a large-scale area closure on patterns of fishing disturbance and the consequences for benthic communities. ICES Journal of Marine Science, 60: 371-380.

EC 2007. European Parliament legislative resolution of 11 December 2007 on the Council common position for adopting a directive of the European Parliament and of the Council establishing a Framework for Community Action in the field of Marine Environmental Policy. (2007) b. Marine Strategy Framework Directive 9388/2/2007 C6-0261/2007 - 2005/0211(COD).

EC 2008a. Directive 2008/56/EC of the European Parliament and of the Council of 17 June 2008 establishing a framework for community action in the field of marine environmental policy (Marine Strategy Framework Directive). In Official Journal of the European Union, pp. 19-40.

EC 2008b. Establishing a framework for community action in the field of marine environmental policy (Marine Strategy Framework Directive). 2008/56/EC: 40.

EC 2008b. The role of the CFP in implementing an ecosystem approach to marine management. SEC(2008) 449.

Elliott, M. 2002. The role of the DPSIR approach and conceptual models in marine environmental management: an example for offshore wind power. Marine Pollution Bulletin, 44: Iii-Vii.

FAO 2003. Fisheries management. 2. The ecosystem approach to fisheries. . FAO Technical Guidelines for Responsible Fisheries No. 4: 112.

Fletcher, W. J. 2005. The application of qualitative risk assessment methodology to prioritize issues for fisheries management. ICES Journal of Marine Science, 62: 1576-1587.

Fletcher, W. J., Shaw, J., Metcalf, S. J., and Gaughan, D. J. 2010. An ecosystem-based fisheries management framework: the efficient, regional-level planning tool for management agencies. Marine Policy, 34: 1226-1238.

Francis, R. I. C. 1992. Use of risk analysis to assess fishery management strategies - a casestudy using orange roughy (Hoplostethus atlanticus) on the Chatham Rise, New Zealand. Canadian Journal of Fisheries and Aquatic Sciences, 49: 922-930.

Fraser, H. M., Greenstreet, S. P. R., and Piet, G. J. 2009. Selecting MPAs to conserve ground fish biodiversity: the consequences of failing to account for catchability in survey trawls. ICES Journal of Marine Science, 66: 82-89.

Goodsir, F., Bloomfield, H. J., Judd, A., Kral, F., Robinson, L. A., and Knights, A. M. In press. A pressure-based expert-driven approach to assess and manage the combined effects of human activities in marine ecosystems. ICES Journal of Marine Science.

Greenstreet, S. P. R., Fraser, H. M., and Piet, G. J. 2009. Using MPAs to address regionalscale ecological objectives in the North Sea: modelling the effects of fishing effort displacement. ICES Journal of Marine Science, 66: 90-100. 
Halpern, B. S., Selkoe, K. A., Micheli, F., and Kappel, C. V. 2007. Evaluating and ranking the vulnerability of global marine ecosystems to anthropogenic threats. Conservation Biology, 21: 1301-1315.

Haynes, G. A. 2009. Testing the boundaries of the choice overload phenomenon: The effect of number of options and time pressure on decision difficulty and satisfaction. Psychology \& Marketing, 26: 204-212.

HELCOM (2013): Approaches and methods for eutrophication target setting in the Baltic Sea region. Balt. Sea Environ. Proc. No. 133

Hobday, A.J., Smith, A.D.M., Stobutzki, I.C., Bulman, C., Daley, R. and J.M. Dambacher. 2011. Ecological risk assessment for the effects of fishing. Fisheries Research 108 (2): 372-384

Holman, I. P., Nicholls, R. J., Berry, P. M., Harrison, P. A., Audsley, E., Shackley, S., and Rounsevell, M. D. A. 2005. A regional, multi-sectoral and integrated assessment of the impacts of climate and socio-economic change in the UK: II Results. Climatic Change, 71: 43-73.

Hope, B. K. 2006. An examination of ecological risk assessment and management practices. Environment International, 32: 983-995.

Horwood, J.W., Nichols, J.H., Milligan, S. Evaluation of closed areas for fish stock conservation (1998) Journal of Applied Ecology, 35 (6), pp. 893-903.

Jeffrey, R. C. 1983. The logic of decision. University of Chicago Press, Chicago, Illinois, USA.

Jeffrey, R. C. 1992. Probability and the art of judgement. Cambridge University Press, Cambridge, UK.

JRC (2011): MSFD GES TSG Marine Litter: Galgani F, Piha H, Hanke G, Werner S, Alcaro L, Mattidi

Kappel, C. V. 2005. Losing pieces of the puzzle: threats to marine, estuarine, and diadromous species. Frontiers in Ecology and the Environment, 3: 275-282.

Knights, A. M., Koss, R. S., and Robinson, L. A. 2013. Identifying common pressure pathways from a complex network of human activities to support ecosystem-based management. Ecological Applications.

Knights, A. M., Piet, G. J., Jongbloed, R., Tamis, J. E., and Robinson, L. A. Submitted. Evaluating the risks to marine ecosystems from human activities using an exposureeffect approach. Biological Conservation.

Knights, A.M., Culhane, F., Hussain, S.S., Papadopoulou, K.N., Piet, G.J., Raakær, J., Rogers, S.I., Robinson, L.A., 2014. A step-wise process of decision-making under uncertainty when implementing environmental policy. Environmental Science \& Policy 39, 56-64.

La Jeunesse, I., Rounsevell, M., and Vanclooster, M. 2003. Delivering a decision support system tool to a river contract: a way to implement the participatory approach principle at the catchment scale? Physics and Chemistry of the Earth, 28: 547-554.

Leslie, H. M., and McLeod, K. L. 2007. Confronting the challenges of implementing marine ecosystem-based management. Frontiers in Ecology and the Environment, 5: 540-548.

Levin, P. S., Fogarty, M. J., Murawski, S. A., and Fluharty, D. 2009. Integrated Ecosystem Assessments: Developing the Scientific Basis for Ecosystem-Based Management of the Ocean. Plos Biology, 7: 23-28.

Liu, J. G., Dietz, T., Carpenter, S. R., Alberti, M., Folke, C., Moran, E., Pell, A. N., et al. 2007. Complexity of coupled human and natural systems. Science, 317: 1513-1516.

National Research Council, Marine protected areas: tools for sustaining ocean ecosystems. National Academy Press, Washington, DC (2001) 
Odermatt, S. 2004. Evaluation of mountain case studies by means of sustainability variables A DPSIR model as an evaluation tool in the context of the North-South discussion. Mountain Research and Development 24:336-341.

Odermatt, S. 2004. Evaluation of mountain case studies by means of sustainability variables A DPSIR model as an evaluation tool in the context of the North-South discussion. Mountain Research and Development, 24: 336-341.

OSPAR (2008): Towards the 50\% reduction target for nutrients. Assessment of Implementation of PARCOM Recommendations 88/2 and 89/4. ISBN 978-1-90585949-8, Publication Number: 310/2008.

Peter J.S. Jones, Collective action problems posed by no-take zones, Marine Policy, Volume 30, Issue 2, March 2006, Pages 143-156

Resnik, M. D. 1987. Choices: An introduction to decision theory. University of Minnesota Press, Minneapolis, Minnesota, USA.

Rice, J. C., and Rochet, M. J. 2005. A framework for selecting a suite of indicators for fisheries management. ICES Journal of Marine Science, 62: 516-527.

Robinson, L.A., White, L., Culhane, F.E. and Knights, A.M. 2013. ODEMM Pressure Assessment Userguide (Version 2). ODEMM Guidance Document Series No.4. EC FP7 project (244273) 'Options for Delivering Ecosystem-based Marine Management. University of Liverpool.

Samhouri, J., and Levin, P. S. 2012. Linking land- and sea-based activities to risk in coastal ecosystems. Biological Conservation, 145: 118-129.

Scheren, P. A. G. M., Kroeze, C., Janssen, F. J. J. G., Hordijk, L., and Ptasinski, K. J. 2004. Integrated water pollution assessment of the Ebrie Lagoon, Ivory Coast, West Africa. Journal of Marine Systems, 44: 1-17.

Smith, A. D. M., Fulton, E. J., Hobday, A. J., Smith, D. C., and Shoulder, P. 2007. Scientific tools to support the practical implementation of ecosystem-based fisheries management. ICES Journal of Marine Science, 64: 633-639.

Technical Research Centre of Finland (VTT) (2009, June 25). Ship Wastewater Discharges Cause Minor Though Not Insignificant Nutrient Input In The Baltic Sea. ScienceDaily. Retrieved April 26, 2013, from http://www.sciencedaily.com/releases/2009/06/090625074508.htm?utm_source=feedb urner\&utm_medium $=$ feed\&utm_campaign $=$ Feed $\% 3 \mathrm{~A}+$ sciencedaily $+\% 28$ ScienceDail $\mathrm{y} \% 3 \mathrm{~A}+$ Latest + Science + News $\% 29$

UN. 1997. Glossary of Environment Statistics, Studies in Methods, Series F, No. 67, United Nations, New York.

UN. 2005. United Nations General Assembly. World Summit Outcome, Resolution A/60/1, adopted by the General Assembly on 15 September 2005. Retrieved on: 2009-02-17.

van Vliet, M., Dubbink, W. 1999. Evaluating governance:State, Market and Participation Compared, Aldershot: Ashgate.

Williams, A., Dowdney, J., Smith, A. D. M., Hobday, A. J., and Fuller, M. 2011. Evaluating impacts of fishing on benthic habitats: A risk assessment framework applied to Australian fisheries. Fisheries Research, 112: 154-167.

Zacharias, M. A., and Gregr, E. J. 2005. Sensitivity and vulnerability in marine environments: an approach to identifying vulnerable marine areas. Conservation Biology, 19: 86-97.

Zhou, S., Smith, A.D.M. and M. Fuller. 2011. Quantitative ecological risk assessment for fishing effects on diverse data-poor non-target species in a multi-sector and multi-gear fishery. Fisheries Research 112 (3): 168-178 